Jurnal Ilmu Manajemen, Volume 2, Nomor 1, Maret 2016

\title{
PERANAN KOMUNIKASI PEMASARAN, CITRA MEREK DAN KEPERCAYAAN MEREK TERHADAP KESETIAAN MEREK
}

\author{
Rahayu Mardikaningsih, Ella Anastasya Sinambela \\ Universitas Mayjen Sungkono, Mojokerto
}

\begin{abstract}
The retail business that continues to grow requires every company engaged in the retail sector to always carry out various strategies in order to expand market coverage and the number of customers. The existence of a number of loyal customers can ensure the survival of the company so that it must be continuously worked on and improved for the progress of the company. This study aims to analyze and determine the effect of marketing communication, brand image, and brand trust on brand loyalty. The research method used is a quantitative method with the analysis technique of Structural Equation Modeling (SEM). The intended respondents are Indomaret customers in the city of Surabaya, totaling 100 respondents using purposive sampling technique. The results showed that marketing communication, brand image, and brand trust had a significant effect on brand loyalty.
\end{abstract}

Key words: marketing communication, brand image, brand trust, brand loyalty

\begin{abstract}
ABSTRAK
Bisnis ritel yang terus berkembang mengharuskan setiap perusahaan yang bergerak di bidang ritel untuk senantiasa melakukan berbagai strategi agar dapat memperluas cakupan pasar dan jumlah pelanggan. Keberadaan jumlah pelanggan setia dapat menjamin kelangsungan hidup perusahaan sehingga hal tersebut harus terus diusahakan dan ditingkatkan demi kemajuan perusahaan. Penelitian ini bertujuan untuk menganalisis dan mengetahui pengaruh komunikasi pemasaran, citra merek, dan kepercayaan merek terhadap kesetiaan merek. Metode penelitian yang digunakan adalah metode kuantitatif dengan teknik analisis Structural Equation Modeling (SEM). Responden yang dituju adalah pelanggan Indomaret di Kota Surabaya yang berjumlah 100 responden dengan teknik pengambilan sampel secara purposif. Hasil penelitian menunjukkan bahwa komunikasi pemasaran, citra merek, dan kepercayaan merek memiliki pengaruh yang signifikan terhadap kesetiaan merek.

Kata-kata kunci: komunikasi pemasaran, citra merek, kepercayaan merek, kesetiaan merek
\end{abstract}


Implikasi manajerial yang lain dari penelitian ini antara lain adalah meningkatkan komunikasi pemasaran terutama tentang merek dengan merencanakan strategi yang tepat untuk materi dan sasaran komunikasi serta menetapkan target yang relevan dari keberhasilan komunikasi agar terus memperoleh kesan positif dari pasar sasaran. Hubungan masyarakat tetap terus ditingkatkan agar memperkuat upaya pencitraan sehingga mereka terus menerus memperoleh pengetahuan tentang produk dan merek. Khusus untuk merek diupayakan untuk terus mendapatkan kepuasan dan kepercayaan konsumen.

\section{PENUTUP}

Penelitian ini menunjukkan bahwa komunikasi pemasaran, citra merek, dan kepercayaan merek memiliki pengaruh yang signifikan terhadap kesetiaan merek. Di penelitian ini, seluruh hipotesis yang diuji menunjukkan hasil telah mendukung penelitian-penelitian sebelumnya. Keterbatasan dari penelitian ini adalah hanya melibatkan variabel komunikasi pemasaran, kepercayaan merek, citra merek, dan kesetiaan merek. Penelitian lanjutan perlu dilakukan untuk melibatkan variabel-variabel yang relevan dengan variabel terikat kesetiaan merek seperti variabel asosiasi merek, variabel sikap merek, variabel ekuitas merek, ekuitas pelanggan bahkan resonansi merek. Responden dapat dikembangkan cakupan dan jumlahnya agar kemampuan menggeneralisasi hasil penelitian ini akan menjadi lebih baik.

\section{DAFTAR PUSTAKA}

Ahmed, S. \& Rahman, H. 2015. The Effects of Marketing Mix on Consumer Satisfaction: A Literature Review from Islamic Perspectives. Turkish Journal of Islamic Economics, 2(1), pp: 17-30

Alida, P, 2007. Pengaruh Nilai Pelanggan, Kepuasan terhadap Loyalitas Nasabah Tabungan Perbankan di Sulawesi Selatan, Jurnal Manajemen dan Kewirausahaan, 9(1), hal: 73-81

Amir, M. T. 2006. Manajemen Ritel, Cetakan Pertama, Penerbit PPM, Jakarta.

Armstrong, G. \& Kotler, P. 2009. Marketing: an introduction. $7^{\text {th }}$ edition. United States of America: Pearson Education, Inc.

Autami, N. L. M. 2015. Pengaruh Retail Mix Terhadap Keputusan Pembelian Konsumen Pada Gerai Chatime. E-Jurnal Manajemen Unud, 4(11), hal: 38823908

Banu, K. D. 2014. The Antecedents of Store Image and Customer Satisfaction. International Journal of Research in Business and Social Science, 3(3), pp: 48-62 
Ciendra, I. dan Hartono, S. 2014. Pengaruh Retail Mix Terhadap Loyalitas Konsumen Dengan Customer Satisfaction Sebagai Variabel Intervening Di Giordano Ciputra World Surabaya. Jurnal Manajemen Pemasaran Petra, 2(1), hal: 1-9

Darmawan, Didit. 2002. Dampak Kesan Kualitas Rumah Makan terhadap Minat Mereferensikan, Jurnal Bisnis, Ekonomi dan Sosial, Vol.3 No.1 Juli, 1-12

Darmawan, Didit. \& Hendratno D.S. 2003. Dampak Kepuasan Nasabah terhadap Loyalitas Nasabah dan Perilaku Menabung, Jurnal Bisnis, Ekonomi dan Sosial, Vol.3 No.2 Januari, 1-19

Darmawan, Didit. 2003. Teori Pengambilan Keputusan. Universitas Atmajaya, Yogyakarta Darmawan, Didit. 2003. Mengukur Efektivitas Iklan, Jurnal Bisnis, Ekonomi dan Sosial, Vol.4 No.1 Juli, 105-119

Darmawan, Didit. 2003. Tantangan Pemasaran Partai Politik Menjelang Pemilu 2004, Jurnal Ekonomi-Manajemen, Vol.2 No.2 Desember, 73-90

Darmawan, Didit. \& Erna Ferrinadewi. 2003. Dampak Publik Figure sebagai Product Endorser terhadap Minat Pembeli Konsumen, Jurnal Media Komunikasi Ekonomi dan Manajemen, Vol.2 No.1 September, 27-33

Darmawan, Didit. 2003. Studi Tentang Tingkat Kepuasan Penumpang Kapal Feri Penyebrangan Ujung Kamal (Persiapan Strategik Menghadapi Dioperasikannya Suramadu), Jurnal Ekonomi-Manajemen, Vol.2 No.2 Desember, 25-43

Darmawan, Didit. \& Budiyanto. 2004. Pengukuran Citra Merek Produk Sepeda Motor, Jurnal Ilmiah Manajemen dan Akuntansi, Vol.1 No.1 Januari, 99-111

Darmawan, Didit. 2004. Pengaruh Persepsi Kualitas Layanan, Citra Merek, dan Kepuasan Nasabah terhadap Respon Perilaku Nasabah, Jurnal Ilmiah Manajemen dan Akuntansi, Vol.1 No.1 Januari, 33-47

Darmawan, Didit. 2004. Pengaruh Variabel Psikologis, Harga dan Kelompok Acuan terhadap Keputusan Konsumen Membeli Produk Minuman Suplemen, Jurnal Media Komunikasi Ekonomi dan Manajemen, Vol.3 No.1 September, 14-23 
Djati, S. Pantja \& D. Darmawan. 2004. Pengaruh Kesan Kualitas Layanan, Harga dan Kepuasan mahasiswa PTS terhadap Minat Mereferensi Kampusnya, Jurnal Widya Manajemen dan Akuntansi, Vol.4 No.2 Agustus, 190-204

Djati, S. Pantja \& D. Darmawan. 2005. Pengaruh Kinerja Karyawan terhadap Kepuasan, Kepercayaan, dan Kesetiaan Pelanggan, Jurnal Manajemen dan Kewirausahaan, Vol.7 No.1 Maret, 48-59

Dwi, A. dan Febrina, R. 2010. Pengaruh Kualitas Layanan Terhadap Kepuasan Pelanggan dalam Membentuk Loyalitas Pelanggan. Jurnal Ilmu Administrasi dan Organisasi, 17(2), hal: 114-126

Ferrinadewi, Erna \& D. Darmawan. 2004. Perilaku Konsumen: Analisis Model Keputusan, Universitas Atma Jaya, Yogyakarta

Gunawan, Aditya., Setya Arum, R. Mahyanaila, Hikmatul Khasanah. 2019. Perilaku Konsumen dan Pemasaran Strategik, Spektrum Nusa Press, Jakarta

Handoko, V. Rudy. \& Didit Darmawan. 2004. Pengaruh Kinerja Wiraniaga dan Karakter Demografinya terhadap Kinerja Pasar Perusahaan, Jurnal Ilmu-Ilmu Sosial dan Humaniora, Vol.8 No.1 Juli, 63-72

Heide, M., Olsen, S.O., \& Dopico, D.C. 2010. The Influence of Test Situation and Satisfaction with Preparation on Evaluation and Intention to Consume a New Seafood Product. British Food Journal, Vol. 112, No.7, pp: 763-774.

Iskandar, Mochamad. \& D. Darmawan. 2003. Strategi Pemasaran, IntiPresindo Pustaka, Bandung

Karina, Ana., Toni Baskoro K. \& D. Darmawan. 2012. Pengantar Psikologi, Addar Press, Jakarta

Katrine, Vela \& Sandy Sharman. 2014. Pemasaran, Nusadua Press, Bali

Khasanah, Hikmahtul, Setya Arum, D. Darmawan. 2010. Pengantar Manajemen Bisnis, Spektrum Nusa Press, Jakarta

Kotler, P. \& Keller. K.L. 2009. Manajemen Pemasaran, Edisi 13, Jilid 1 dan 2, Jakarta: Erlangga.

Levy, Michael \& Weitz, Barton A. 2009. Retailing Management (7th Ed.). New York: McGraw-Hill Irwin.

Mahyanaila, R. 2016. Manajemen. Addar Press, Jakarta

Martin, D., Consuegra, Molina, A., \& Esteban, A. 2007. An Integrated Model of Price, Satisfaction and Loyalty: An Empirical Analysis in the Service Sector. Journal of Product and Brand Management, Vol. 16, No. 7, pp: 459-468. 
Pasaribu, D. dan Sembiring, B. 2012. Pengaruh Strategi Bauran Pemasaran Ritel Terhadap Kepuasan dan Loyalitas Pelanggan Minimarket Mes Mart Syariah. Jurnal Ilmu Ekonomi dan Bisnis, 2(1), hal: 1-10

Purnamasari, Eliasinta., D. Darmawan, D. Baskara. 2002. Bauran Pemasaran dan Kualitas Layanan serta Pengaruhnya terhadap Kepuasan dan Loyalitas Pelanggan, Jurnal Ilmu Manajemen, Vol 3 No1, 34-46

Santoso, Alfa.B.P. 2012. Pengaruh Retail Marketing Mix Terhadap Loyalitas Konsumen dengan Kepuasan Konsumen Sebagai Pemoderasi. Jurnal RMB, 7(2), hal: $97-113$

Setyaningsih \& Didit D. 2004. Pengaruh Citra Merek terhadap Efektifitas Iklan, Jurnal Media Komunikasi Ekonomi dan Manajemen, Vol.2 No.3 Mei, 41-49

Sivadas, Eugene \& Jamie L. Baker-Prewitt. 2000. AnExamination of The RelationshipBetween Service Quality, Customer Satisfaction, and Store Loyalty. International Journal of Retail and Distribution Management.28(2), Page 73-82

Sjamsi, Nurul \& Didit Darmawan. 2004. Peran Startegis Layanan pada Penyelenggaraan Pelayanan Publik, Jurnal Administrasi Publik, Vol.1 No.1 Desember, 83-95

Sugiyanto \& Yolanda. 2013. Analisis Kepuasan Pelanggan (Studi Kasus Minimarket Indomaret). Jurnal Ekonomi, 15(2), hal: 185-197

Supiatni, N. 2012. Penilaian Konsumen Terhadap Penerapan Bauran Pemasaran Ritel pada Toko Segar Buah Denpasar. Jurnal Bisnis dan Kewirausahaan, 8(2), hal: $20-29$

Ujianto \& Didit D. 2003. Rasionalitas Mahasiswa dalam Memilih Partai Politik: Studi terhadap Faktor yang Dipertimbangkan Mahasiswa Kota Surabaya dalam Memilih Partai Politik, Jurnal Ilmu-Ilmu Sosial dan Humaniora, Vol.7 No.1 Juli, 43-54

Utami, W. C. 2008. Manajemen Retail: Strategi dan Implementasi Ritel Modern. Jakarta: PT. Salemba Empat.

Virvilaite, R., Saladiene, V., \& Skindaras, D. 2009. The Relationship between Price and Loyalty in Service Industry". Journal of the Commerce of Engineering Decisions, 3 pp: 96-104.

Wahyudi, Ikhsan., D. Bhaskara, D. Darmawan, Hermawan \& N. Damayanti. 2006. Kinerja Organisasi dan Faktor-Faktor Pembentuknya, Jurnal Ekonomi dan Bisnis, Volume 4 Nomor 2, November, 95-108 
Wahyuni, I. 2008. Pengaruh Sistem Pelayanan dan Kepuasan Terhadap Loyalitas. Nasabah BMT Mitra Usaha Mulia Tempel Sleman. Skripsi Sarjana Ekonomi Manajemen. Yogyakarta: Universitas Islam Negeri Sunan Kalijaga.

Werdati, F. Manajemen Pemasaran, Dua Saudara Press, Bandung. 